\title{
Decrease in Device Pressure
}

National Cancer Institute

\section{Source}

National Cancer Institute. Decrease in Device Pressure. NCI Thesaurus. Code C63255.

Unintended decrease in pressure, compromising a medical device's intended function. 